\title{
Infected Thyroglossal Duct Cyst - A Diagnostic Dilemma
}

\author{
Ramhari Shankarrao Sathawane ${ }^{1}$, Kshitija Sanjay Bhakte ${ }^{2}$, Prajkta Sathawane Moharkar ${ }^{3}$, \\ Vidyarjan Ashok Sukhadeve ${ }^{4}$, Mrunali Gajanan Chincholkar ${ }^{5}$ \\ 1, 2, 3, 4, 5 Department of Oral Medicine \& Radiology, Swargiya Dadasaheb Kalmegh \\ Smruti Dental College \& Hospital, Nagpur, Maharashtra, India.
}

\section{INTRODUCTION}

Neck swellings are usually the most visible and noticeable pathologies. These swellings include enlarged lymph nodes, swellings of thyroid gland, congenital / developmental cysts and lipomas. ${ }^{1}$ Cystic congenital neck masses are usually very well diagnosed in childhood. Congenital cystic masses of the anterior neck include thyroglossal duct cyst (TDC), branchial cleft cyst \& cystic hygromas from uncommon pathologies to very rare thymic and bronchogenic cysts. ${ }^{2}$ Painless and soft or fluctuant nature of neck mass is usually the first clinical presentation in most cases. Ultrasonography (USG) helps to define the size, shape and extent of mass and confirms the cystic nature of lesion, whereas histopathological examination is the gold standard. ${ }^{3}$

The purpose of this article is to impress upon all that USG is an adjuvant imaging modality which helps in diagnosing cystic nature of the neck lesions. But most of the time, it cannot differentiate between dermoid cyst and thyroglossal cyst. The present case of infected thyroglossal duct cyst was reported to have diagnostic dilemma between clinical diagnosis and sonographic diagnosis. Histopathological examination confirmed the clinical diagnosis of Infected TDC.

\section{PRESENTATION OF CASE}

A 23-year-old female came to Out Patient Department of Oral Medicine and Radiology with a chief complaint of swelling in the front region of neck since 6 months. She also complained of pain on deglutition since 2 months. She was afebrile. Her vital parameters were within normal limits.

On examination, the face and neck was bilaterally symmetrical except a single ovoid swelling present in anterior neck in the midline extending superoinferiorly 2 $\mathrm{cm}$ below, from the body of the hyoid bone up to the cricoid cartilage \& mediolaterally from medial border of left sternohyoid to right sternohyoid muscle, approximately 2 * $3 \mathrm{~cm}$ in size with well-defined margins (Fig. 1a). It moved upwards while swallowing and on protrusion of tongue. Skin over the swelling was normal.
Corresponding Author: Dr. Kshitija Sanjay Bhakte, 28, 'Maitra', Dhawad Layout, Katol, Nagpur - 441302, Maharashtra, India.

E-mail: kshitijabhakte1316@gmail.com

DOI: $10.14260 / \mathrm{jemds} / 2021 / 418$

How to Cite This Article:

Sathawane RS, Bhakte KS, Moharkar PS, et al. Infected thyroglossal duct cyst - a diagnostic dilemma. J Evolution Med Dent Sci 2021;10(27):2044-2047, DOI: $10.14260 /$ jemds/2021/418

Submission 01-03-2021, Peer Review 05-05-2021, Acceptance 12-05-2021, Published 05-07-2021.

Copyright (C) 2021 Ramhari Shankarrao Sathawane et al. This is an open access article distributed under Creative Commons Attribution License [Attribution 4.0 International (CC BY 4.0)] 


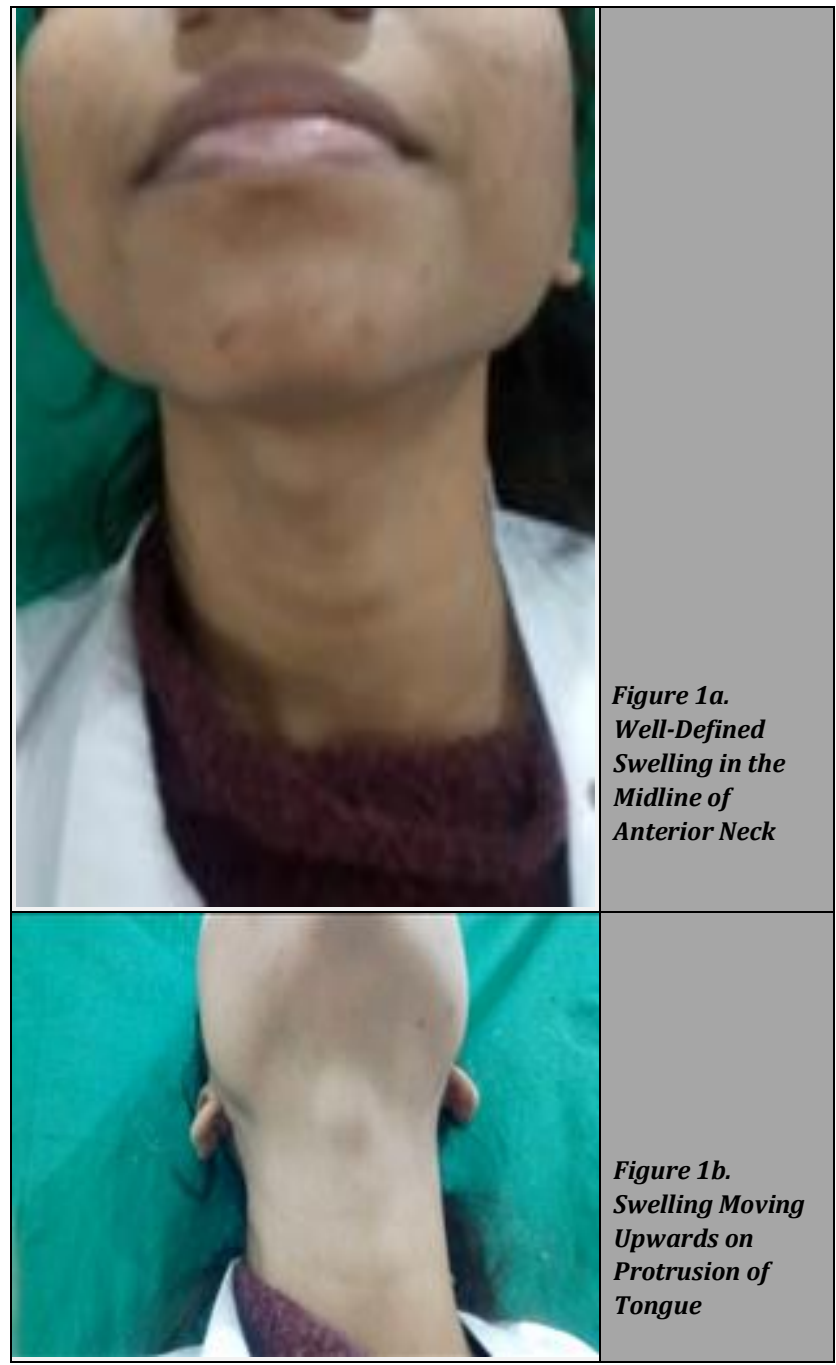

All findings on inspection were confirmed by palpation. There was no rise in local temperature over the swelling. On bidigital palpation, the swelling was smooth and soft in consistency. Swelling was compressible and tender. Trans illumination test was negative. The interincisal opening was $36 \mathrm{~mm}$. On intraoral examination there was no hard tissue abnormality, Stains ++, Calculus+. Soft tissues of oral cavity including tongue revealed no abnormality.

Based on clinical findings a provisional diagnosis of Infected Thyroglossal duct cyst was made.

The haematological investigation (CBC, BT, CT, RBS) reports \& Urine Analysis reports were within normal limits.

The patient was advised USG which revealed a cystic lesion of $18 * 17 * 11 \mathrm{~mm}$ in base of tongue right sub mentally with a solid component of $5 * 5 \mathrm{~mm}$. There was an evidence of vascularity in the solid component. Both the thyroid lobes were normal in size, shape \& appearances with no evidence of cystic or solid lesion in both lobes. Isthmus was normal. There was no evidence of retrosternal extension, abnormal calcification or cervical lymphadenopathy. Sonographically the lesion was diagnosed as dermoid cyst. The patient was then subjected to Fine needle aspiration cytology (FNAC) which yielded colourless viscous fluid without lymphocytes or abnormal cells within it, suggesting the cystic lesion of TDC.

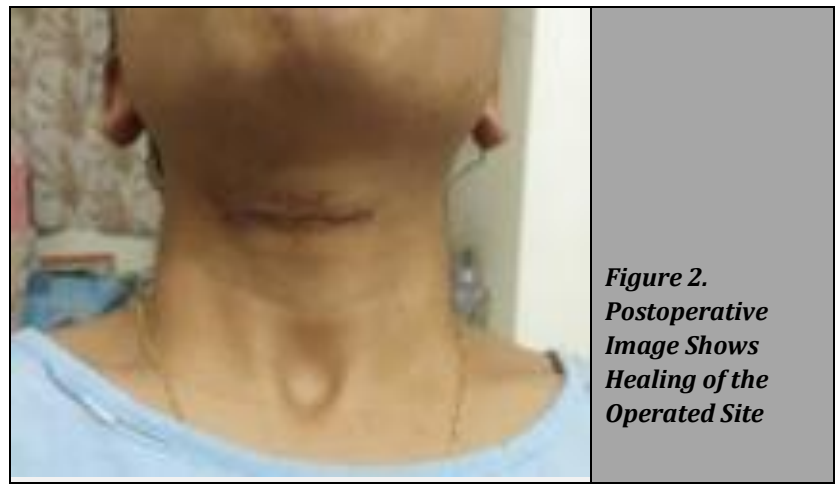

Patient was posted for midline cyst excision under general anaesthesia after her medical examination. Under all aseptic conditions cyst was excised along with some middle part of hyoid bone and surrounding tissue by Sistrunk procedure. Wound was closed in layers putting a drain which was removed after 3 days. The postoperative healing was uneventful.

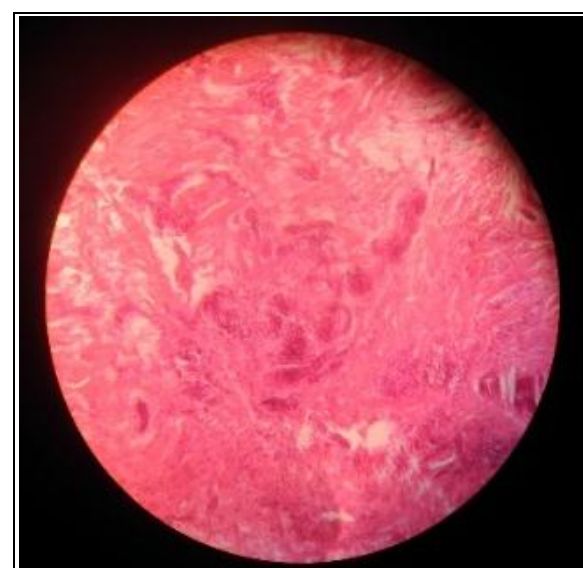

Fig 3 a-Depicts Non-Specific Connective Tissue with lymphoid Aggregates

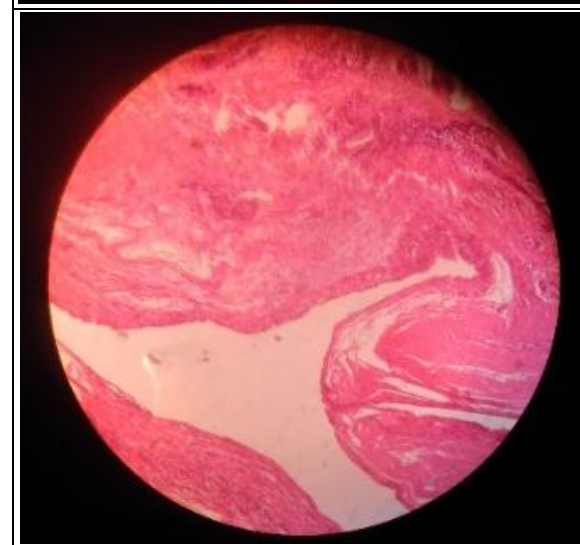

Fig 3 b- Depicts Cyst Wall Lined by Squamous Cells with Flattened Epithelium

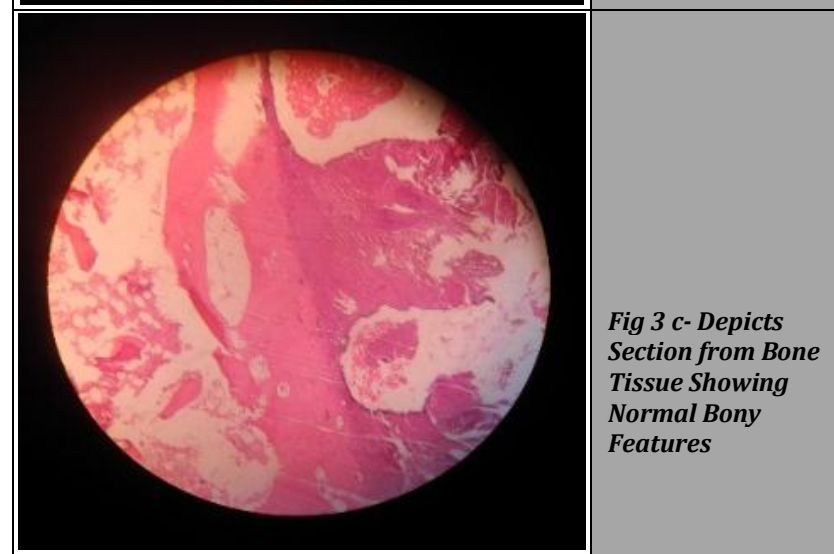


The specimen was sent for histopathological examination which revealed nonspecific connective tissue with lymphoid aggregates (Fig. 3a) and cyst wall was lined by squamous cells, with flattened epithelium (Fig. 3b). The section from bone tissue showed normal bony features (Fig. 3c). The histopathological findings were consistent with the provisional diagnosis of infected thyroglossal duct cyst.

\section{DISCUSSION}

Most cervical swellings of specific aetiology are found mostly in expected anatomical areas occurring at particular age groups. This helps the clinician to formulate a provisional diagnosis, differential diagnosis and appropriate treatment protocol for the patient. ${ }^{4}$ Congenital, developmental, and traumatic swellings are fairly predictable in their locations. Literature search revealed description of a "Golden rule of 7" which says that the average time for the appearance of clinical features of neck swellings caused by infection, tumours and congenital pathologies is 7 days, 7 months and 7 years respectively. ${ }^{1}$ Among all the swellings, lymph node enlargement is the most common, followed by epidermoid cyst, lipoma, thyroglossal cyst, branchial cyst \& benign vascular lesion.

During embryogenesis, the primitive thyroid gland develops from foramen cecum at $17^{\text {th }}$ week of intrauterine life. It grows downward as a bilobed diverticulum in front of the pharynx, and assumes its normal position in the anterior neck by $7^{\text {th }}$ week. During its descent, the thyroid gland is attached to tongue by a tubular tract known as thyroglossal duct. By $10^{\text {th }}$ week of gestation, this duct usually disappears. But, if it persists, it usually presents as a cystic lesion (Fig. 4). Sometimes the infection may occur and the lesion is labelled as infected thyroglossal duct cyst. ${ }^{5}$

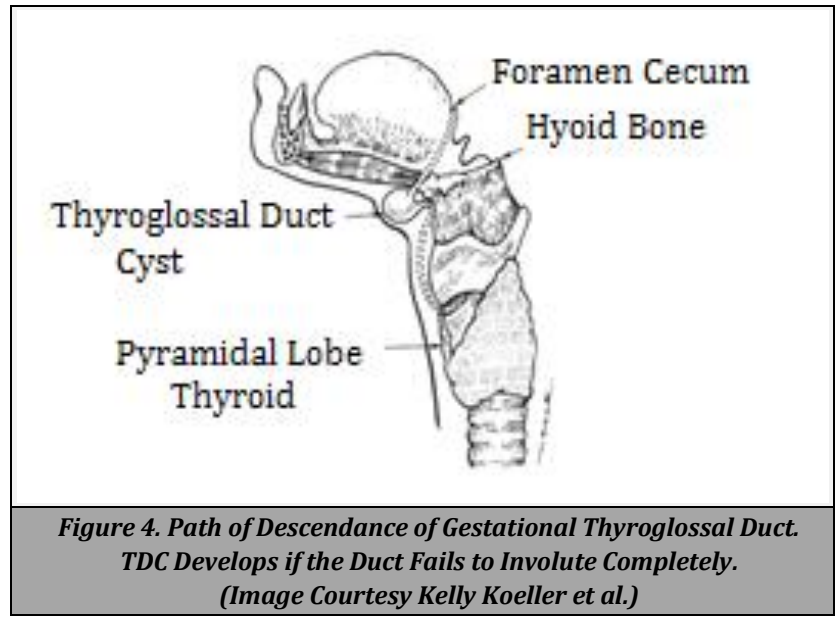

Thyroglossal duct cyst is commonly encountered in the paediatric population and up to one third of cases seen in adults with the age range from birth to 70 years; $50 \%$ occurring before 20 years of age. There is no gender predilection. An average size of these cysts is about $2-4 \mathrm{~cm}$, whereas larger ones are less profound, if present it is more common in adults. ${ }^{6}$ It can occur anywhere from the base of the tongue to the suprasternal region within this tract. About 90 $\%$ of TDC are found in the midline and remaining on the left side usually near midline. ${ }^{7}$ Mostly it appears as a painless, slowly growing swelling. Patient experiences pain if it is infected. Patient may complain of difficulty in breathing if the large swelling compresses the trachea. ${ }^{8}$ Generally, these cysts have tendency to move on deglutition and move upwards on protrusion of tongue. Secondary infection can cause these cysts to enlarge, and patient often reports with symptoms of pain and difficulty in swallowing. In most cases, sonography combined with FNAC is sufficient for its pre-treatment evaluation. Fine needle aspiration reveals colourless fluid. Histopathologically, the cyst lining usually shows squamous, simple cuboidal, or transitional epithelial cells. ${ }^{9}$ Stroma mostly shows some inflammatory cells. Thyroid cysts are not lined by squamous epithelium which is the primary difference between TDC and thyroid cyst. ${ }^{10}$ Thorough histological examination is essential to rule out carcinoma. On USG, TDC is seen as an anechoic and well encapsulated lesion. ${ }^{11}$ Cyst lining usually secretes proteinaceous content and this gives the cyst a pseudo solid appearance. Solid component in the cystic wall seen in sonography needs to be evaluated thoroughly on histopathological examination to differentiate it from carcinoma. ${ }^{12}$ The most common cystic lesion of dermoid cyst should be considered in differential diagnosis of TDC. Dermoid cysts and epidermoid cysts develop as a result of sequestration of ectodermal tissue. The dermoid cyst contains mixture of keratin and sebaceous material. FNAC reveals the cystic fluid as homogenous hypo attenuating fluid material. ${ }^{13} \mathrm{~A}$ "Sistrunk" procedure is the recommended procedure of choice in the management of TDC which consists of excision of the thyroglossal duct cyst, along with some middle part of the hyoid bone, and the surrounding tissue around the thyroglossal tract. The recurrence rate following this procedure is $5 \% .14$

In the present case, the cystic lesion moved upwards on deglutition and also on protrusion of tongue, pointing towards the diagnosis of TDC. The history of pain on deglutition and tender swelling on palpation was suggestive of infected thyroglossal duct cyst. Many a times TDC cannot be differentiated from dermoid cyst on USG examination. Hence, histopathological examination is necessary for its diagnosis and to rule out carcinoma. The histopathological report has confirmed a diagnosis of infected TDC in our case.

Financial or other competing interests: None.

Disclosure forms provided by the authors are available with the full text of this article at jemds.com.

\section{REFERENCES}

[1] Pandey AK, Bhardwaj A, Maithani T, et al. Distributive analysis of head and neck swellings with their cytopathological correlation. Otorhinolaryngology Clinics: An International Journal 2016;8(3):89-96.

[2] Mittal MK, Malik A, Sureka B, et al. Cystic masses of neck: a pictorial review. Indian $\mathrm{J}$ Radiol Imaging 2012;22(4):334-43.

[3] Denise L. Jackson evaluation and management of paediatric neck masses: an otolaryngology perspective. Physician Assist Clin 2018;3(2):245-69. 
[4] Giglio JA, Laskin DM. Establishing the differential diagnosis of neck lesions. Quintessence Int 2000;31(9):637-41.

[5] Rosen RD, Sapra A. Embryology, thyroid. In: Statpearls. Treasure Island (FL): Statpearls Publishing 2021 Jan.

[6] Patigaroo SA, Dar NH, Jallu AS, et al. Thyroglossal duct cysts: a clinicosurgical experience. Indian J Otolaryngol Head Neck Surg 2017;69(1):102-7.

[7] Gandhi RA, Bhowate R, Degweker S, et al. Infected thyroglossal duct cyst involving submandibular region: a case report. Case Rep Dent 2011;2011:978263.

[8] Schwetschenau E, Kelley DJ. The adult neck mass. Am Fam Physician 2002;66(5):831-9.

[9] Soni S, Poorey VK, Chouksey S. Thyroglossal duct cyst, variation in presentation, our experience. Indian J Otolaryngol Head Neck Surg 2014;66(4):398-400.
[10] Ahuja AT, King AD, King W, et al. Thyroglossal duct cysts: sonographic appearances in adults. Am J Neuroradiol 1999;20(4):579-82.

[11] Koeller KK, Alamo L, Adair CF, et al. Congenital cystic masses of the neck: radiologic pathologic-correlation. Radiographics 1999;19(1):121-46.

[12] Harnsberger H. Handbook of head and neck imaging. $2^{\text {nd }}$ edn. St Louis: Mosby 1995.

[13] Dermawan JK, Chute DJ. Educational case: developmental neck masses and other neck tumors. Acad Pathol 2019;6:2374289519888735.

[14] Hirshoren N, Neuman T, Udassin R, et al. The imperative of the Sistrunk operation: review of 160 thyroglossal tract remnant operations. Otolaryngol Head Neck Surg 2009;140(3):338-42. 